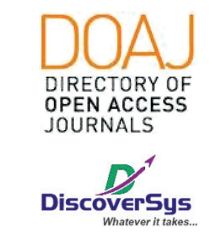

Published by DiscoverSys

\section{Hubungan antara obesitas dan insiden kanker kolorektal di RSUP Sanglah tahun 2016-2017}

\author{
Anak Agung Sagung Mirah Trisuladara, ${ }^{1 *}$ Made Agus Dwianthara Sueta, ${ }^{2}$ \\ Made Suka Adnyana ${ }^{2}$
}

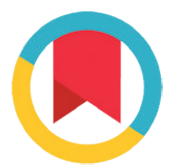

CrossMark

\title{
ABSTRAK
}

Latar Belakang: Kanker kolorektal merupakan penyakit keganasan ketiga di Indonesia dengan peningkatan posisi dari posisi keenam. Kondisi obesitas merupakan salah satu faktor risiko kanker kolorektal. Penelitian ini bertujuan untuk mengetahui hubungan antara obesitas dan usia dengan insiden kanker kolorektal di RSUP Sanglah.

Metode: Penelitian ini merupakan penelitian analitik case-control, dengan total sampel berjumlah 274 yang terbagi ke dalam kelompok penderita kanker kolorektal (137 orang) dan non-kanker kolorektal (137 orang). Sumber data adalah data sekunder yang diperoleh dari rekam medis pasien tahun 2016-2017 di RSUP Sanglah. Hubungan antara karakteristik penderita obesitas dan insiden kanker kolorektal dianalisis dengan Chi-square dan anlisis resiko.

Hasil: Hasil penelitian menunjukkan bahwa penderita pada kelompok kanker kolorektal lebih banyak $(53,3 \%)$ berjenis kelamin laki-laki,sedangkan pada kelompok non kanker kolorektal penderita perempuan lebih banyak (50,4\%). Rata-rata usia penderita kanker kolorektal 54 tahundan non kanker kolorektal 42 tahun. Berdasarkan kelompok Body Mass Index (BMI), penderita kanker kolorektal sebagian besar (62\%) berada pada kelompok obesitas, sedangkan pada penderita obesitas non-kanker kolorektal sebanyak 39,4\%. Hasil analisis menunjukkan terdapat hubungan yang signifikan antara obesitas dan insiden kanker kolorektal dengan nilai $p<0,001$, dengan peningkatan risiko terkena kanker kolorektal sebesar 1,588 kali lebih tinggi pada penderita dengan $\mathrm{BMI} \geq 23,00 \mathrm{~kg} / \mathrm{m}^{2}$ (IK 95\% 1,2352,040). Hasil uji Chi-square juga menunjukkan terdapat hubungan yang signifikan antara usia $\geq 40$ tahun dan insiden kanker kolorektal dengan nilai $p<0,001(<0,05)$.

Simpulan: Melalui hasil penelitian ini dapat disimpulkan bahwa secara statistik terdapat hubungan yang signifikan antara obesitas dan usia di atas 40 tahun dengan insiden kanker kolorektal.

Kata kunci: obesitas, usia, BMI, kanker kolorektal

Cite This Article: Trisuladara, A.A.S.M., Sueta, M.A.D., Adnyana, M.S. Hubungan antara obesitas dan insiden kanker kolorektal di RSUP Sanglah tahun 2016-2017. Intisari Sains Medis 10(2): 297-300. D0I: 10.15562/ism.v10i2.278

\section{ABSTRACT}

'Program Studi Pendidikan Dokter Fakultas Kedokteran Universitas Udayana

${ }^{2}$ Bagian/SMF IImu Bedah Fakultas Kedokteran Universitas Udayana, RSUP Sanglah Denpasa, BaliIndonesia.

*Correspondence to: Anak Agung Sagung Mirah Trisuladara, Program Studi Pendidikan Dokter Fakultas Kedokteran Universitas Udayana trisuladara@gmail.com

Diterima: $16-06-2018$

Disetujui: 02-07-2018

Diterbitkan: 01-08-2019
Introduction: Colorectal cancer is the third malignant disease in Indonesia. Obesity is one of the risk factors related to colorectal cancer. This research aims to role out relationships between obese and age to the incidence of colorectal cancer at Sanglah General Hospital.

Method: Study design using case-control analytic model, covering 274 samples, divided into the group of colorectal cancer (137 persons) and non-cancer samples (137 persons). Secondary data were used for analysis obtained from medical records in year period of 2016-2017 at Sanglah General Hospital. Data were analyzed using Chi-square analysis and risk estimate model.

Result: The result showed that the majority of colorectal cancer patients were male (53.3\%), meanwhile for non-cancer patients were female (50.4\%). The average age of colorectal cancer patients was 54 years old while 42 years for non-colorectal cancer patients. Based on the BMI groups, majority of cancer colorectal patients (62\%) belongs to obese, while only $39.4 \%$ for non-colorectal cancer patients. Result of analysis showed that there is significant relationship between obese and the incidence of colorectal cancer ( $p$ value $<0.001$ ), with the risk increase of prevalence by 1.588 times higher for those patients with $\mathrm{BMI} \geq 23.00 \mathrm{~kg} / \mathrm{m}^{2}$ (95\% Cl 1.235-2.040). Result from the Chi-square test also indicated that there is significant relationship between age above 40 years and the incidence of colorectal cancer ( $p$ value $<0.001$ ).

Conclusion: It can be concluded that there is significant relationships between obese and age above 40 years to the incidence of colorectal cancer. 


\section{PENDAHULUAN}

Jumlah kasus kanker yang disebabkan oleh obesitas diperkirakan sebesar 20\% dengan peningkatan risiko keganasan yang dipengaruhi oleh diet, perubahan berat badan, distribusi lemak, serta aktivitas fisik. ${ }^{1}$ The International Agency for Research into Cancer (2002) dan The World Cancer Research Fund melaporkan bahwa kanker yang umum terjadi pada orang dengan obesitas ialah endometrial, esofagus adenokarkinoma, kolorektal, payudara postmenopausal, prostat, dan renal. Karsionoma kolorektal menduduki posisi ketiga keganasan terbanyak di dunia dan penyebab kematian kedua terbanyak di Amerika Serikat. ${ }^{2}$ Peningkatan berat badan lebih dari $21 \mathrm{~kg}$ setelah mencapai tahap kedewasaan pada laki-laki memiliki risiko $60 \%$ terserang kanker kolorektal dibandingkan dengan yang memiliki peningkatan berat badan $1-5 \mathrm{~kg} .{ }^{1}$

Berdasarkan data Globocan 2012, insiden kanker kolorektal di Indonesia adalah 12,8 per 100.000 penduduk usia dewasa, dan mortalitas 9,5\% dari seluruh kasus kanker. Di Indonesia, kanker kolorektal berada di posisi ketiga dari penyakit keganasan. Kenaikan dari posisi keenam menjadi posisi ketiga disebabkan oleh perubahan pada diet orang Indonesia, baik karena peningkatan kemakmuran dan pergeseran ke arah cara makan orang Barat (westernisasi) dengan diet lebih tinggi lemak serta rendah serat., ${ }^{3,4}$

Hasil kajian Kokki (2013) menyebutkan bahwa angka kasar rata-rata kejadian kanker kolorektal di Asia Tenggara untuk laki-laki dan perempuan adalah 6,95/100.000 populasi dan insiden ini meningkat seiring dengan bertambahnya umur. ${ }^{5}$ Ma dkk (2013) menyebutkan bahwa insiden kanker kolorektal di dunia memiliki rentang usia antara 40 sampai 84 tahun. ${ }^{6}$

Tidak dijumpai hasil kajian mengenai obesitas dan insiden kanker kolorektal di Indonesia. Hasil penelitian Munawaroh (2012) menyebutkan insiden dan mortalitas kanker usus besar, selain itu karakteristik pasien kanker kolorektal dengan usia, jenis kelamin, obesitas, serta penatalaksanaannya. ${ }^{7}$ Berdasarkan latar belakang di atas, menarik dikaji hubungan antara kelebihan berat badan dan obesitas dan insiden kanker kolorektal di Indonesia, khususnya di Bali. Penelitian ini bertujuan untuk menganalisis hubungan antara obesitas dan insiden kanker kolorektal dan menganalisis hubungan antara usia $\geq 40$ tahun dan insiden kanker kolorektal di RSUP Sanglah.

\section{METODE}

Penelitian ini merupakan penelitian analitik dengan rancangan penelitian kasus kontrol (case-control) dengan pengambilan data hanya satu kali pada setiap responden. Penelitian ini mengkaji hubungan antara faktor-faktor risiko dan dampaknya terhadap insiden kanker kolorektal. Konsep penelitian ini menitikberatkan pada variabel BMI sebagai pengukuran obesitas pada insiden kanker kolorektal di RSUP Sanglah Denpasar.Variabel lainnya yang menjadi fokus adalah usia penderita kanker kolorektal. Penelitian ini dilakukan di RSUP Sanglah dan pengambilan data rekam medis tahun 2016-2017.

Populasi target dalam penelitian ini adalah seluruh pasien kanker kolorektal dan obesitas di Indonesia. Sedangkan populasi terjangkau dalam penelitian ini adalah pasien kanker kolorektal dan non-kanker kolorektal yang menjalani perawatan di RSUP Sanglah. Sampel dalam penelitian ini adalah populasi terjangkau yang memenuhi kriteria inklusi dan eksklusi. Kriteria inklusi pada penelitian ini yaitu data pasien kanker kolorektal dan non kanker kolorektal yang menjalani perawatan di RSUP Sanglah, sedangkan kriteria eksklusi pada penelitian ini yaitu data pasien kanker kolorektal yang tidak lengkap meliputi nama, jenis kelamin, usia, dan $\mathrm{BMI}<18,50 \mathrm{~kg} / \mathrm{m}^{2}$.

Pengambilan data rekam medis dilakukan di Rumah Sakit Sanglah untuk pasien kanker kolorektal data tahun 2016-2017. Berdasarkan data rekam medis terdapat 137 pasien penderita kanker kolorektal dan seluruh pasien dipakai sebagai sampel (metode sensus). Hal ini sudah memenuhi syarat besarnya sampel dan sebagai pembanding jumlah pasien non-kanker kolorektaldiambil sebanyak 137 pasien dengan metode acak.

Data diinput ke dalam program SPSS versi 17.0. Analisis data dilakukan dengan menggunakan prevalensi dan distribusi frekuensi.Kriteria objektif penelitian adalah berdasarkan kelompok BMI normal $\left(\geq 18,50-22,99 \mathrm{~kg} / \mathrm{m}^{2}\right)$ dan obesitas $\left(\geq 23,00 \mathrm{~kg} / \mathrm{m}^{2}\right)$ serta berdasarkan kelompok umur $<40$ tahun dan $\geq 40$ tahun. Analisis hubungan antara insiden kanker kolorektal dan usia dan jenis kelamin diuji melalui analisis Chi-Square dan analisis resiko.

\section{HASIL}

Pada penelitian ini akan dijabarkan mengenai hubungan kanker kolorektal dengan faktor risiko seperti obesitas dan usia $\geq 40$ tahun pada 274 subjek penelitian yang berbasis data rekam medis. Sebanyak 137 orang dengan kanker kolorektal dikelompokkan sebagai kelompok kasus dan 137 orang normal sebagai kelompok kontrol. Karakteristik subjek kelompok kasus dan kelompok disajikan pada Tabel 1. 
Tabel 1 Karakteristik subjek kelompok kasus dan kontrol

\begin{tabular}{lccc}
\hline Variabel & Kelompok Kasus & Kelompok Kontrol & $\boldsymbol{p}$ \\
\hline Usia (Rerata) & 54 & 42 & $<0,001$ \\
Jenis Kelamin & & & \\
Laki-laki & $73(53,3 \%)$ & $68(49,6 \%)$ & \\
Perempuan & $64(46,7 \%)$ & $69(51,4 \%)$ & \\
\hline
\end{tabular}

Tabel 2 Analisis risiko obesitas dan usia terhadap kanker kolorektal

\begin{tabular}{llccccc}
\hline Variabel & & $\begin{array}{c}\text { Kelompok } \\
\text { Kasus }\end{array}$ & $\begin{array}{c}\text { Kelompok } \\
\text { Kontrol }\end{array}$ & OR & IK 95\% & $\boldsymbol{p}$ \\
\hline Obesitas & Obesitas & $85(62 \%)$ & $54(39,4 \%)$ & 1,588 & $1,235-$ & $<0,001^{\star}$ \\
& Tidak obesitas & $52(38 \%)$ & $83(60,6 \%)$ & & 2.040 & \\
\multirow{2}{*}{ Usia } & $\geq 40$ tahun & $119(86,86 \%)$ & $74(54,02 \%)$ & 2,775 & $1,819-$ & $<0,001^{\star}$ \\
& $<40$ tahun & $18(13,14 \%)$ & $63(45,98 \%)$ & & 4,233 &
\end{tabular}

${ }^{*}$ signifikan $(\mathrm{p}<0,05)$

Berdasarkan Tabel 1, didapatkan umur rata-rata pada kelompok kasus pada penelitian ini adalah 54 tahun dan pada kelompok kontrol 42 tahun. Sampel berjenis kelamin laki-laki lebih banyak dibandingkan dengan perempuan pada kelompok kasus. Jumlah laki-laki pada sampel kelompok kasus sebanyak 73 orang (53,3\%) dan 64 orang $(46,7 \%)$ perempuan. Kelompok kontrol menunjukkan kondisi yang berbeda, dimana jumlah perempuan sebanyak 69 orang $(50,4 \%)$ dan laki-laki sebanyak 68 orang $(49,6 \%)$.

Selanjutnya adalah analisis risiko terhadap hubungan antara obesitas dan usia terhadap kanker kolorektal (Tabel 2).

Analisis risiko obesitas terhadap kanker kolorektal dapat diketahui bahwa pada kelompok kasus sebanyak 85 orang (62\%) tergolong obesitas. Berdasarkan analisis Odd Ratio didapatkan nilai $\mathrm{OR}=1,588$ (IK 95\%: 1,235 - 2.040; $\mathrm{p}<0,001$ ), dapat disimpulkan bahwa peluang ditemukan orang dengan obesitas 1,5 kali lebih besar pada kelompok orang yang berisiko tinggi kanker kolorektal dibandingkan dengan kelompok orang yang berisiko rendah kanker kolorektal, hal tersebut bermakna secara statistik bahwa obesitas merupakan faktor risiko untuk kanker kolorektal (Tabel 2).

Analisis hubungan antara usia dan kanker kolorektal, ditemukan bahwa pada kemompok usia $\geq 40$ tahun lebih banyak menderita kanker kolorektal dibandingan dengan kelompok yang tidak menderita kanker kolorektal dengan proporsi $86,86 \%$. Melalui analisis risiko didapatkan nilai $\mathrm{OR}=2,775$ (IK 95\%: 1,819 - 4,233; p <0,001). Berdasarkan hal tersebut maka peluang untuk menemukan orang dengan usia $\geq 40$ tahun 2,7 kali lebih besar pada kelompok yang menderita kanker kolorektal dibandingan dengan kemlompok yang tidak menderita kanker kolorektal, hal tersebut signifikan secara statistik dan usia $\geq 40$ tahun merupakan suatu faktor risiko untuk kanker kolorektal. (Tabel 2)

\section{PEMBAHASAN}

Peningkatan angka kejadian disertai prevalensi faktor risiko kanker kolorektal di beberapa negara di Asia dan Eropa Timur diantaranya disebabkan oleh diet yang tidak baik, obesitas, dan merokok. ${ }^{8}$ Peningkatan berat badan lebih dari $21 \mathrm{~kg}$ setelah mencapai tahap kedewasaan pada laki-laki memiliki risiko 60\% terkena kanker kolorektal dibandingkan dengan yang memiliki peningkatan berat badan 1-5 kg., ${ }^{1,8,11}$

Berdasarkan hasil uji statistik didapatkan bahwa terdapat hubungan yang signifikan antara obesitas dan insiden kanker kolorektal dengan nilai $\mathrm{p}<0,001$ (Tabel 2). Hal ini sejalan dengan hasil penelitian Frezza dkk (2006) bahwa erdapat hubungan antara BMI obesitas dengan kanker kolorektal $(\mathrm{p}=0,000)$. Obesitas lebih mempengaruhi laki-laki dibandingan dengan perempuan, dimana risiko terkena kanker kolorektal meningkat pada laki-laki dengan kelompok BMI tertentu. Akan tetapi dengan adanya peningkatan berat badan maka risiko terkena kanker kolorektal akan lebih meningkat pada perempuan dibandingkan laki-laki. ${ }^{9}$

Hasil penelitian Ma dkk (2013) menunjukkan risiko peluang kanker kolorektal pada kelompok obesitas dan kelompok BMI normal sebesar 1,334 dengan IK 95\% 1,253-1,420.6,10

Peningkatan BMI berkaitan dengan peningkatan risiko keganasan. Pada laki-laki dengan peningkatan BMI sebesar $5 \mathrm{~kg} / \mathrm{m}^{2}$ berhubungan erat dengan kanker kolon ( $R R$ 1,24; p <0,001). 
Namun hubungan erat yang lebih lemah antara peningkatan BMI dan kanker rektal pada laki-laki, dan kanker kolon pada perempuan. ${ }^{10}$

Hasil penelitian menunjukkan bahwa terdapat hubungan yang signifikan antara penderita kanker kolorektal dan usia di atas 40 tahun. Hasil penelitian Ma dkk (2013) menyebutkan bahwa insiden kanker kolorektal di dunia memiliki rentang usia antara 40 sampai 84 tahun. $^{6}$

\section{SIMPULAN}

Hasil penelitian ini menunjukkan bahwa terdapat hubungan yang signifikan antara obesitas dan insiden kanker kolorektal. Kelompok obesitas memiliki peluang faktor risiko terkena kanker kolorektal sebesar 1,588 kali dibandingkan dengan orang dengan BMI normal. Terdapat hubungan yang bermakna antara usia dan insiden kanker kolorektal penderita dengan usia 40 tahun ke atas memiliki risiko 2,775 kali lebih tinggi untuk terkena kanker kolorektal dibandingkan dengan penderita berusia di bawah 40 tahun.

\section{DAFTAR PUSTAKA}

1. De Pergola G and Silvestris F. Obesity as a Major Risk Factor for Cancer. Journal of Obesity. 2013;2(2):1-11.

2. Siegel RL, Miller KD, Jemal A. Cancer Satistics. Cancer Journal for Clinicians American Cancer Society. 2015;65(5):5-29.
3. Nainggolan O, Maria A, Marice N. Faktor-faktor Berhubungan dengan Tumor/Kanker Saluran Cerna Berdasarkan Survei Kesehatan Nasional. Majalah Kedokteran Indonesia. 2009;59(11):510-517.

4. Wargasetia TL. Memahami Kaitan Obesitas dan Kanker: Peluang untuk Pencegahan Kanker. Berkala Ilmiah Kedokteran Duta Wacana. 2016;1(3):219-228.

5. Kokki I, Papana A, Campbell H, Theodoratou E. Estimating the incidence of colorectal cancer in South East Asia. Croatian Medical Journal. 2013;54(1):532-540.

6. Ma Y, Yang Y, Wang F, Zhang P, Shi C, Zou Y, Qin H. Obesity and Risk of Colorectal Cancer: A Systematic Review of Prospective Studies. PLOS ONE. 2013;8(1):1-16.

7. Munawaroh IR. Gambaran Profil Penderita Kanker Usus Besar dan Penatalaksanaannya di RSUP Dr. Moewardi .Surakarta: Universitas Muhammadiyah Surakarta.

8. Torre LA, Bray F, Siegel RL, Ferlay J, Lortet-Tieulent J. Global Cancer Statistics. CA Cancer J Clin. 2012;65(2):87-108.

9. Frezza EE, Wachtel MS, Chiriva-Internati M. Influence of Obesity on The Risk of Developing Colon Cancer. Gut Journal. 2006;55(1):285-291.

10. Renehan AG, Tyson M, Egger M, Heller RF, Zwahlen M. Body-mass index and incidence of cancer: a systematic review and meta-analysis of prospective observational studies. The Lancet. 2008; 371(9612):569-578.

11. World Health Organization. 2006. BMI classification. [Online] Tersedia di: http://apps.who.int/bmi/index. jsp?introPage=intro_3.html [diunduh: 29 Desember 2016].

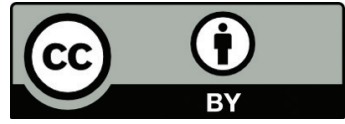

This work is licensed under a Creative Commons Attribution 